\title{
EL FILÓSOFO Y EL TEÚRGO EN EL PENSAMIENTO DE JÁMBLICO: UNA METAFÍSICA DEL SÍMBOLO
}

\author{
PHILOSOPHER AND THEURGE IN THE \\ THOUGHT OF IAMBLICHUS:
}

A METAPHYSICS OF THE SYMBOL

\author{
María Jesús Hermoso Félix \\ Universidad de Valladolid
}

RESUMEN: La razón de la convivencia en el pensamiento Jámblico de una valoración incontestable de la filosofía con una sólida presencia de la teúrgia plantea un reto a la crítica contemporánea. Desde los parámetros actuales de interpretación se hace difícilmente comprensible esta convivencia que parece, en su núcleo mismo, contradictoria. Pese a la recuperación paulatina de la importancia y la seriedad de este filósofo, muchos puntos quedan sin resolver. Se hace necesario ensayar un nuevo marco interpretativo capaz de dar razón de la convergencia entre filosofía y teúrgia en el pensamiento de Jámblico, respetando su coherencia interna y buscando el sentido y la solidez de su propuesta. En la búsqueda de este marco, la naturaleza y la función del símbolo ha de ser determinante. La comprensión de la figura del teúrgo en el pensamiento de Jámblico adquirirá sentido en este marco interpretativo.

*Profesora ayudante de Filosofía, mjhermosofelix@yahoo.es 
Comenzaremos por delimitar las cuestiones fundamentales: La comprensión misma de filosofía que encontramos en los pensadores de raigambre platónica y, en general, en época clásica; la presencia del lenguaje de los misterios en la filosofía de Platón; el contexto histórico por el que atraviesa Jámblico y, con él, la filosofía pagana del momento. Posteriormente pasaremos a reflexionar acerca de la comprensión de lo divino presente en el De Mysteriis. Todos estos elementos nos llevarán a la conclusión de que Jámblico no propone una introducción del irracionalismo sino la lectura de la teúrgia desde la planta teórica que le brinda la filosofía platónica y las mediaciones que ésta desarrolla.

Palabras Clave: Filosofo, teúrgo, símbolo, Jámblico, Neoplatonismo.

Aвstract:The coexistence of an indisputable valuation of philosophy and a substantial presence of theurgy in the thought of Iamblichus poses a challenge to contemporary studies. Within current interpretative parameters, it is difficult to understand that both are present simultaneously, since at their very core they seem contradictory. In spite of the gradual recovery of the importance and seriousness of his thought that is taking place at present, many points remain unsolved. A new interpretative framework is needed to account for the convergence of philosophy and theurgy in the thought of Iamblichus, respecting its internal coherence and searching for the meaning and soundness of what he proposes. The profound theoretical implications of the notion of symbol are crucial in the search for this framework. This framework will help us to understand the nature and function of the theurge in the thought of Iamblichus. I will begin by defining the key issues: 1) the understanding of philosophy found in the Platonic tradition and thinkers in general, in classical times, 2) the presence of the language of mystery in the philosophy of Plato, and 3) the historical context in which Iamblichus moves, along with the pagan philosophy of that time. Later we will reflect on the understanding of the divine in the De Mysteriis. All these elements lead us to the conclusion that Iamblichus does not propose to introduce irrationalism but rather to read theurgy from the theoretical framework that Platonic philosophy and the mediations it develops provide.

KeYwords: Philosopher, theurge, symbol, Iamblichus, Neoplatonism.

\section{Introducción}

Analizar la naturaleza y la significación de la figura del teúrgo en el pensamiento de Jámblico plantea una serie de retos; abre lugares que dan qué pensar en relación con la emergencia en su filosofía de esta misteriosa figura. La obra de Jámblico, muy especialmente el De Mysteriis, ha supuesto un verdadero 
quebradero de cabeza para la crítica contemporánea, que ha tendido a ver en él la rendición de la razón frente a las fuerzas de la superstición en una época de angustia ${ }^{1}$. Esta línea de interpretación se ha visto compensada en los últimos años por la aportación de especialistas que han puesto en valor su filosofía, buscando un marco de comprensión que diera cuenta de su complejidad y su sentido ${ }^{2}$.

Este artículo busca ahondar en esta línea de recuperación del pensamiento de Jámblico, proponiendo la exploración de una vía posible de interpretación de esta figura, tan compleja para la mentalidad contemporánea. Esta vía posible parte necesariamente de la consideración de una serie de elementos que han de ser tomados en cuenta de cara a allanar el camino hacia la compresión de la figura del teúrgo, tan alejada de lo que hoy entendemos por filosofía. Los enumeramos a continuación:

1. El primero de ellos es la comprensión misma de filosofía que encontramos en los pensadores de raigambre platónica y, en general, en época clásica ${ }^{3}$.

2. El segundo es la consideración de la presencia del lenguaje de los misterios en la filosofía de Platón ${ }^{4}$.

3. El tercero supone una puesta en escena del contexto histórico por el que atraviesa Jámblico y, con él, la filosofía pagana del momento.

El análisis detallado de cada una de estas cuestiones exigiría por sí mismo el espacio de varias monografías. Nosotros nos limitaremos a señalar los puntos que nos resultan fundamentales de cara a nuestro estudio.

${ }_{1}$ Este es el caso de Dodds que apela al De Mysteriis como "un manifiesto del irracionalismo, una afirmación de que la salvación no se encuentra en la razón sino en el ritual” (Dodds, 1994, 270). Del mismo modo afirma que "a las mentes acobardadas de los paganos del siglo IV este mensaje les ofrecía un consuelo”. Esta afirmación no hace, en modo alguno, justicia a uno de los periodos más prolijos de la historia de la filosofía, donde a partir de la obra platónica culmina un complejo proceso hermenéutico y de sistematización sin precedentes.

2 Nos referimos a estudiosos como B.D. Larsen, G. Shaw, C.V. Liefferinge o E.C. Clarke, que desde la seriedad y el rigor han procurado rescatar el pensamiento de Jámblico, ofreciendo exégesis respetuosas con el sentido de su obra.

3 Sobre esta cuestión son de especial relevancia los estudios al respecto llevados a cabo por P. Hadot (Hadot, 2004).

${ }^{4}$ E. Des Places ofrece un análisis interesante de la cuestión en su artículo "Platon et la langue des mystères" (E. D. Places, 1981). Sobre la cuestión de Platón y los misterios órficos disponemos de un trabajo excelente de Alberto Bernabé (Bernabé, 2011). 
Delimitados estos tres elementos a tomar en cuenta, pasaremos a reflexionar acerca de la comprensión de lo divino presente en el De Mysteriis con el fin de poder interpretar el sentido de la figura del teúrgo como figura mediadora entre el hombre y lo divino. La comprensión de lo divino quedará vinculada al ámbito mismo de constitución causal de lo real. No encontramos una noción hipostasiada de los dioses como entidades que, lejos del mundo, influyeran en él o sobre los que se pudiese influir. El teúrgo no es una figura que influya en los dioses para aplacarlos o conseguir beneficios. Esta concepción es refutada en el De Mysteriis, donde se insiste en que los dioses no son seres sometidos a pasión.

A partir de aquí, veremos cómo emerge el sentido de la conexión entre la figura del teúrgo y la del filósofo. Esta conexión quedará establecida por la relación existente entre las nociones de símbolo y belleza en tanto que ámbitos de mediación en el camino hacia el saber acerca de esa dimensión causal de constitución de la realidad.

La convergencia entre lo que hoy entenderíamos como religión y la filosofía toma fuerza en las páginas de los pensadores de este periodo. La consideración del sentido epistémico del mito y el ritual, su interpretación desde un marco teórico-filosófico, toma el lugar protagonista en la reflexión. En este contexto, encontramos en el pensamiento de Jámblico la valoración de la figura del teúrgo, conviviendo en su obra con la profunda valoración que hace de la figura del filósofo. A este aparente contrasentido se le han intentado proponer diversas soluciones, ninguna de ellas satisfactoria. Des Places apunta a una doble personalidad de Jámblico 5 , B. D. Larsen a una supuesta anterioridad del Protréptico sobre el De Mysteriis, que él mismo reconoce como difícil de determinar ${ }^{6}$.

La coexistencia de estas dos figuras en la obra de Jámblico guarda una clave importante de comprensión no solo de este pensador sino de todo el Neoplatonismo posterior en su paulatina acentuación de este intento de aproximar el marco teórico de la filosofía y el ámbito del mito y el ritual. De ahí la importancia

5 Cf. Des Places, 1981, p. 337.

${ }^{6}$ B. D. Larsen se inclina por esta hipótesis, aun reconociendo la imposibilidad de situar cronológicamente las obras de Jámblico. Además, si bien la redacción del Protréptico es incierta, el De Mysteriis suele considerarse una obra de juventud, redactada antes de la muerte de Porfirio. (A este respecto, cf. Van Liefferinge. 2000, n. 86). En todo caso, antes de proponer como solución a las supuestas paradojas que plantea la obra de Jámblico una evolución más que incierta de su pensamiento, es necesario explorar su sentido interno, sus líneas de coherencia, por ver si la paradoja no es proyectada por la exégesis misma. 
de pensar la coherencia interna de la coexistencia de estas figuras en su carácter propio, más allá de explicaciones que busquen dar razón de la contradicción a partir de causas externas a la dinámica interna de esta filosofía.

\section{Parámetros de partida para la comprensión de la relación entre la figura del filósofo y la figura del teúrgo en el pensamiento de Jámblico.}

\subsection{La comprensión de la filosofía en la obra platónica.}

Comenzaremos por trazar las líneas básicas de consideración del primer punto propuesto más arriba: la comprensión de la filosofía, de su carácter, de su naturaleza propia ya desde la Antigüedad. Pierre Hadot ha puesto de manifiesto esta cuestión en numerosos estudios, señalando que: "La filosofía se presenta como un modo de vida, como un arte de vivir, como una manera de ser. De hecho, al menos después de Sócrates, la filosofía antigua posee este carácter. Había un estilo de vida socrática y el diálogo socrático era un ejercicio que conducía al interlocutor de Sócrates a ponerse en cuestión, a tomar cuidado de sí, a volver su alma lo más bella y sabia posible (Platón, Apol. 29e 1)” (Hadot, 2002, p. 295).

Efectivamente, al acercarnos al carácter de la filosofía en la Antigüedad, no nos encontramos en primer término con la pretensión de generar un discurso conceptual objetivo que defina y se haga cargo de la realidad en términos de representación. No se trata de representarnos la realidad en el discurso, de asirla racionalmente, de someterla al concepto. Tal vez esa es la noción de filosofía que hoy día nos es familiar, la que se practica en nuestras academias. Este aspecto de la filosofía no es desdeńable pero cabe preguntarse si era el único operante en la atmósfera en la que respira Jámblico. Es importante tomar en cuenta este aspecto para poder acompañar al sentido del puente que éste traza con toda naturalidad.

Jámblico bebe de la noción de filosofía que atraviesa la obra platónica, su comprensión de la auténtica filosofía es el sostén que le permite servirse de ella como marco hermenéutico de las prácticas rituales. "Un volverse del día nocturno hacia el verdadero; una ascensión hacia el ser, de la cual diremos que es la 
auténtica filosofía"; tal es la filosofía que busca Platón, ese "arte del giro ( $\tau \dot{\varepsilon} \chi v \eta$ $\tau \tilde{\eta} \varsigma \pi \varepsilon \rho 1 \alpha \gamma \omega \gamma \tilde{\eta} \varsigma)^{\prime \prime}$ que facilite el volverse del alma hacia el lugar conveniente.

Lejos de la disección de la realidad en el concepto, encontramos una valoración del logos como instrumento, como camino hacia el hallazgo de una verdad que es antepredicativa, que se dirime en la mirada interior del hombre, que trasciende todo discurso. El logos no tiene que ver con la "racionalización", entendida como reducción al concepto sino con una razón” que se abre a un modo de conocimiento que la trasciende sin ser su contrario. La razón es camino, está en medio, es mediación que acompaña al alma en esta vuelta, en este retorno en el que consiste la filosofía. Esta razón está próxima a la belleza como ámbito epistémico, apunta a ella, a su poder transformador. En el centro mismo de la filosofía platónica se halla la potencia activa de la belleza como método privilegiado, como itinerario activo del filosofar. La razón a la que se vincula esta filosofía es indisociable de este itinerario activo que el hombre debe recorrer por sí mismo con la ayuda del logos y de la gracia transformadora de la belleza: "Sólo a la belleza le ha sido dado ser lo más deslumbrante y lo más amable" ${ }^{10}$ leemos en Fedro $250 \mathrm{~d}$ 5. La belleza del mundo tiene la capacidad de allegarse al alma y encantarla, de deslumbrarla en el punto justo, de atraerla gradualmente, poco a poco, suavemente, propiciando un adentramiento en su naturaleza inteligible, un giro hacia ese lugar que buscó siempre la filosofía platónica, un asemejamiento a lo divino.

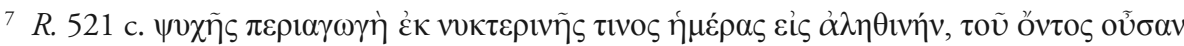

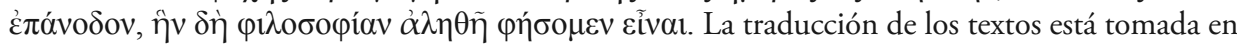
cada caso, con alguna variación, de la versión castellana referida en la bibliografía.

${ }^{8}$ R. $518 \mathrm{~d} 3$

9 En numerosos lugares de sus obras tanto Platón como Plotino despliegan una compleja cartografía del alma en la que la razón en su función lógico-predicativa ocupa un lugar limitado haciéndose hincapié en la necesidad de trascenderla para acceder a la experiencia cumbre de la filosofía. Platón en los libros centrales de la República apela a que el modo de conocimiento que atiende al Bien trasciende la facultad dianoética. Plotino ubicará sobre el modo lógico de

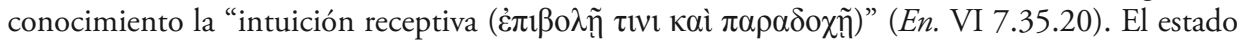
de unificación del alma que procura trasciende todo pensamiento y reflexión en la pura presencia: "No reflexiona entonces sobre sí mismo" (En. IV 4.2.5). Toda dualidad y la posibilidad de todo razonamiento discursivo son trascendidas. De ahí que Plotino diga que: "la dificultad surge precisamente porque la conciencia de aquel no se logra por ciencia (...) sino por una presencia superior a la ciencia” (VI 9.4.1-5). Jámblico se ubicará plenamente en la tradición platónica así entendida.

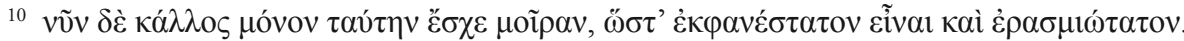


Esta comprensión de la filosofía es la que comparte Jámblico ${ }^{11}$, la que le lleva a establecer un puente con la hermenéutica de las prácticas rituales. La visión del filósofo como aquél que sigue este camino; como aquél que procura la semejanza a lo divino a través de la virtud y la belleza, como veremos, constituye la base de comprensión de la figura del teúrgo. Este transvase de ideas encuentra su lógica y su razón de ser en elementos irrenunciables del pensamiento platónico, que han de ser tomados siempre en cuenta, si queremos hallar el sentido de la transformación que acontece en el Neoplatonismo en esta época.

\subsection{La presencia del lenguaje de los misterios en la obra platónica.}

El segundo elemento que hemos de tomar en consideración es la cercanía y la familiaridad que muestra Platón con el mundo de los misterios, cuyo lenguaje utiliza para referir la experiencia cumbre a la que aspira la filosofía en numerosos lugares de su obra12. Citamos como ejemplo el célebre pasaje de Fedro 249c-249d:

Es necesario, en efecto, que el hombre preste atención al lenguaje de la idea, que va de la multiplicidad de sensaciones a la unificación en el logos. Esto es, por cierto, la reminiscencia de lo que contempló, en otro tiempo, nuestra alma, cuando iba de camino con la divinidad, mirando desde lo alto a lo que ahora decimos que es, y alzando la cabeza a lo que es en realidad. Por eso, es justo que sólo la mente del filósofo sea alada puesto que, en la medida de lo posible, tiene siempre delante de sí, en su memoria, aquellas realidades que, por tenerlas delante, hacen que el dios sea divino. El hombre, pues, que se sirva rectamente de tales rememoraciones, iniciado siempre perfectamente en los misterios perfectos, sólo él llega a ser perfecto verdaderamente ( $\tau \varepsilon \lambda \dot{\varepsilon}$ ov $\varsigma$

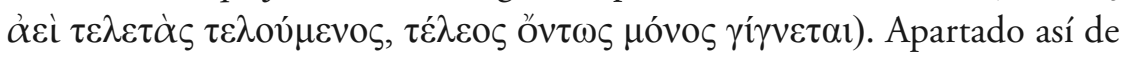
humanos intereses y vuelto a lo divino, es tachado por la multitud como de

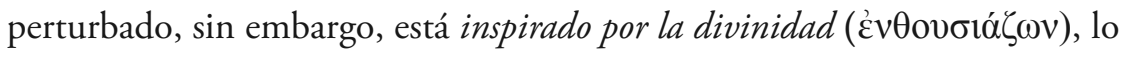
cual escapa a la multitud ${ }^{13}$.

Platón muestra en este pasaje el camino de unificación al que aspira la filosofía con el lenguaje de la iniciación en los misterios. El camino que va de

11 Para un desarrollo más amplio de la cuestión, cf. Hermoso Félix, 2012, p. 353 ss.

12 Cf. por ejemplo, Smp. 209e-211d, Phdr. 250 c, Phd. 69 a-d.

13 La versión castellana de los textos originales está tomada, con alguna variación, de las traducciones citadas en la bibliografía. 
la multiplicidad de las sensaciones, de la fragmentación de la sensibilidad, a la unificación en el logos es vinculado con la reminiscencia de aquello que el hombre contempló en otro tiempo, cuando era "iniciado perfectamente en los misterios perfectos". La unificación en el logos no se delimita como una actividad conceptual, no se trata de acercarse al pensamiento discursivo alejándose de la sensibilidad. Esta unificación es vinculada con la reminiscencia de una contemplación que se significa con el lenguaje de la iniciación. Platón trata de poner de manifiesto el calado y la naturaleza de la experiencia a la que aspira la filosofía y recurre para ello a un lenguaje que era profundamente familiar en su entorno. Éste no tacha como una superstición vacía el ámbito de los misterios sino que utiliza su carga semántica para designar el cariz de aquello que busca el filósofo. El logos que busca el filósofo no lo convierte en una especie de pensador lógico insensible sino en un enamorado de la belleza, en un "inspirado por la divinidad", que se aparta de los intereses de la multitud y retorna a lo divino.

La convergencia entre el lenguaje de la filosofía y el lenguaje de los misterios está ya servida por el propio Platón en su obra; como indica Pepin: "Il a plus d'une fois recouru au rituel et surtout au vocabulaire de l'initiation pour rendre compte de réalités philosophiques" (Pepin, 1993, p. 110) ${ }^{14}$. Desde que éste utilizase el lenguaje de los misterios para referirse al itinerario de la filosofía en el Banquete o describiese la contemplación de la belleza primera en los términos de la iniciación en el Fedro, los pensadores platónicos han pensado en mayor o menor medida, en el sentido de la relación entre la filosofía y los rituales mistéri$\cos ^{15}$. Estos han venido a interpretarse desde el lenguaje de la filosofía platónica, desde su comprensión como camino de liberación del alma y de apertura a la experiencia de lo divino. En este sentido, encontramos un texto paradigmático en la obra de Plotino, en él, el lenguaje y la concepción misma del camino propio de la filosofía platónica sirve de planta para la comprensión de la tarea del sacerdote:

14 Artículo sumamente revelador de la percepción de los misterios y el ritual en la obra platónica. Asimismo, a este respecto es clarificador el artículo de Des Places, 1981.

15 Pepin, en el artículo que venimos de citar (p. 121-122), afirma que: "l'influence exercée dans l'Antiquité par ces textes fondateurs du Phédon et du Phèdre dépasse infiniment la sphère des commentateurs scolaires, auxquels peut se rattacher d'une certaine façon le mathématicien Théon de Smyrne, pour s'étendre à toute la tradition des lecteurs de Platon. Ainsi Plutarque (IerIIe siècle de notre ère) à qui l'on doit plusieurs témoignages sur l'assimilation de la philosophie à l'initiation, une fois au moins fait état dans cette perspective, de la purification : (le jeune homme bien né qui reçoit un blâme ne doit pas se décourager) «mais, comme dans une initiation où la philosophie est son initiatrice, supporter les purifications et la confusion du début dans l'espoir qu'une douceur, une clarté sortiront de l'inquiétude et du trouble du présent " (De audiendo, 16, 47 A) ” 
Los sabios de entre los profetas expresan enigmáticamente el modo en que aquél dios es visto. Mas el sacerdote sabio, descifrando el enigma, puede, llegando hasta allá, hacer real la contemplación del sagrario. Y aunque no llegue hasta allá por considerar que el sagrario es cosa invisible como lo es la Fuente y el Principio, sabrá que la visión es del Principio por un principio, y que el consorcio es también de semejante con semejante, no descuidando ninguna de cuantas cosas divinas es capaz el alma de alcanzar aun antes de la contemplación. El resto lo espera de la contemplación; y el resto, para quien ha rebasado ya todas las cosas, no es sino lo que es anterior a todas las $\operatorname{cosas}^{16}$.

\subsection{Contexto histórico.}

Jámblico se incardina en una corriente de filosofía a la que nunca le fue ajeno el mundo de los misterios. Éste no establece ruptura alguna en este punto sino que ahonda en la tarea de reflexionar sobre la relación entre la filosofía y el ritual desde la convergencia de lenguajes que ya planteara Platón, poniendo el acento en la exégesis de las prácticas rituales del mundo pagano por una apremiante necesidad histórica: revertir un proceso que acabaría con la cosmovisión helénica, a la que pertenecía tanto la filosofía de la Academia como los misterios de Eleusis.

Jámblico utiliza la planta misma de la auténtica filosofía, comprendida por Platón como camino de apertura del alma a la experiencia de lo divino a través de la mediación de la belleza, para generar un marco serio y profundo de comprensión, de ordenación y de criba de los rituales paganos.

Éste busca dignificar los rituales paganos, dar valor a la religión pagana a través de la filosofía de aquél que había erigido en el corazón de su Academia un altar a las Musas. Esta religión, estos rituales, habían abrazado el orden sociocultural en el que se había desarrollado la filosofía platónica, habían sostenido la visión del mundo que alumbrara las diferentes expresiones del paganismo. Con su degradación y su derrumbe, se derrumbaba el orden entero en el que

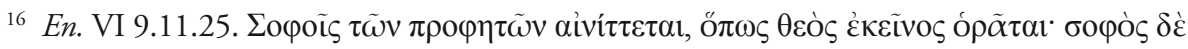

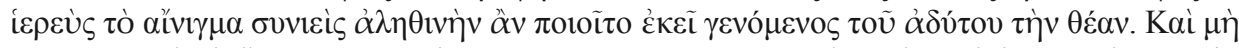

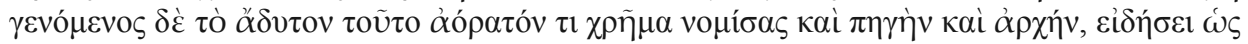

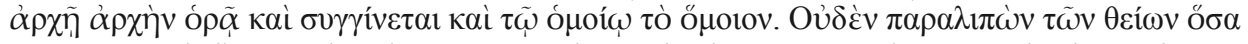

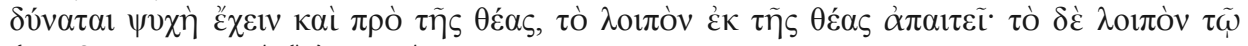

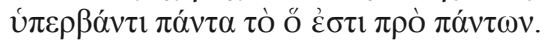


habían habitado los grandes genios del helenismo. La emergencia de una nueva religión amenazaba con relegar a la memoria la estructura misma del mundo en que habitaron los héroes, en que Homero cantaba a sus dioses, en que Sócrates asistía a los simposios, ensalzando los dulces encantos de Eros.

Esta nueva religión gozaba de unos jóvenes rituales, bien enhebrados en un marco teórico que debía mucho a la filosofía platónica. La coherencia entre este marco y sus prácticas rituales daba una gran unidad a todas las clases sociales. Las clases intelectuales y el pueblo compartían un mismo suelo que daba una gran solidez a la propuesta cristiana: Un nuevo mundo emergía y un antiguo mundo declinaba, con él llegaba el ocaso del helenismo. Éste pasaría a formar parte del pasado, a servir de fuente de inspiración de un orden socio-cultural ajeno. La Academia, como lugar emblemático de la filosofía y Eleusis, como lugar emblemático de los misterios, correrían una misma suerte. Ambos pertenecían a una cosmovisión que no sobreviviría a la emergencia de una religión universalista como el cristianismo.

Jámblico era plenamente consciente de esta situación, sabía que si no era posible dar coherencia y solidez a la religión pagana, ésta no podría hacer frente al cristianismo, que el mundo entero que él conocía se vendría abajo. Acomete, entonces, un intento que se incardina en el espíritu mismo de la filosofía platónica y en la convergencia de lenguajes que abriera el propio Platón. Un intento de naturaleza profundamente filosófica: comprender las prácticas rituales del paganismo desde la filosofía platónica. Intenta, así, dotarlas de coherencia y solidez desde un marco teórico firme que permitiera el renacer de la religión pagana, acercando a las clases intelectuales y al pueblo en la causa común de la defensa del helenismo.

No es el pesimismo de un espíritu acobardado, como se ha venido afirmando ${ }^{17}$, el que hace que Jámblico intente dar cuenta de los rituales paganos,

17 El acobardamiento de los filósofos neoplatónicos de la época les habría llevado a conceder un espacio de privilegio al mundo de la religión. Esta sería la causa del acento que se pone en la comprensión de las prácticas rituales, del lugar que les concede la filosofía en este momento. Esta interpretación, deudora de la posición de Dodds, es seguida por estudiosos de la talla de Saffrey. Éste afirma que: "Renonçant à l'effort de la raison, on souhaite donc de sortir de la nuit de l'esprit par un enseignement venu de l'Au-delà et auquel il n'y a plus qu'à ajouter foi” (Saffrey, 1990, p.164). Olvida esta posición el ingente esfuerzo racional que llevan a cabo los filósofos de esta época, intentando llevar a cabo una exégesis coherente del papel epistémico de las prácticas rituales del paganismo. Si de algo da muestras la filosofía de la época es de su potencia exegética, 
intente entender e interpretar las prácticas de la religión pagana, indagando en su valor epistémico. Antes al contrario, es la fortaleza y la potencia filosófica de un espíritu enamorado de su mundo el que lleva a Jámblico a intentar revertir un proceso histórico que amenazaba con derrumbar la vigencia socio-cultural del helenismo. Como apunta Van Liefferinge "Jámblico tiene la intención de revalorizar el rito pagano [...] El De Mysteriis es una obra de recuperación del culto pagano en declive" (1999, p. 124).

Es necesario tener presente la necesidad histórica, para la pervivencia del mundo antiguo, de una renovación de la religión pagana y tomar conciencia de que el mundo de los misterios nunca fue ajeno a la filosofía de raigambre platónica; de que la convergencia entre el lenguaje de la filosofía y el lenguaje mistérico se halla ya en lugares centrales de la obra de Platón. Es necesario no perder nunca de vista la profundidad y el calado de la auténtica filosofía, tal y como la perfilara Platón, irreducible al discurso predicativo, para que emerja el sentido de la relación entre filosofía y teúrgia en el pensamiento de Jámblico. En el marco de esta relación ha de ser comprendida la figura del teúrgo, su coherencia, el valor de esta propuesta que supone un reto para la crítica contemporánea.

Una vez delimitado el enfoque desde el que nos acercaremos a la figura del teúrgo, trataremos de poner de manifiesto el carácter y la naturaleza de esta figura. Comenzamos indagando en los postulados desde los que se abre su comprensión en esta filosofía.

\section{La concepción del principio divino en la filosofía de Jámblico como base fundamental para la comprensión de la figura del teúrgo.}

La figura del teúrgo en el pensamiento de Jámblico tiene una función de mediación entre el hombre y lo divino. Éste es concebido como el hombre sagrado que conserva la comunión entre dioses y hombres ${ }^{18}$. Un punto fundamental en el análisis de esta figura será, por tanto, la indagación en lo que Jámblico entiende por principio divino. De esta comprensión dependerá, en gran medida, la comprensión misma del teúrgo, de su naturaleza y su función.

de la fortaleza teórica que da lugar a la construcción de sistemas que sirven la planta e integración de las diferentes expresiones del helenismo desde el marco de la filosofía platónica.

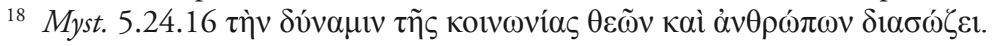


Lo primero a tomar en cuenta es que los dioses no quedan delimitados, en ningún momento, como entidades constituidas de modo separado que se encontraran en algún lugar desde el que influyeran en el mundo de los hombres; de tal modo que se pudiera establecer con ellos una relación que diera como resultado un beneficio determinado o la prevención de algún daño. La mediación a la que se refiere Jámblico no apunta a este marco de relación, objeto de numerosas críticas a lo largo del De Mysteriis. Ésta alude, por el contrario, a un modo mucho más complejo de actividad que parte de una concepción cosmológica donde el principio divino que fundamenta a los seres no está en modo alguno separado del mundo ${ }^{19}$ :

Como la luz está presente en el aire sin mezclarse con él [...] así también la luz de los dioses brilla separadamente y, firmemente estable en sí misma, avanza a través de todos los seres. [...] Lleva a cabo una única continuidad y armonía de todo con todo [...] pues ningún intervalo temporal ni extensión espacial ni división en partes ni ninguna otra equivalencia similar se produce en presencia de los dioses ${ }^{20}$.

Jámblico basa la posibilidad de la teúrgia en la presencia de lo divino en el mundo como principio que conforma a cada uno de los seres en su esencia misma. En De Mysteriis 1.8.52-26 apunta a este vínculo inmanente que hace interdependientes a todas las realidades entre sí: "De los superiores sobrevienen a los inferiores la esencia y la especie, y en los seres mejores primariamente son producidos los posteriores, de modo que de ellos proceden para los inferiores tanto el orden y la medida como lo que cada cosa es en su individualidad". Lo divino constituye, por tanto, un nivel de causación que interpela a los seres en su esencia misma; sin esta comunidad originaria la función del teúrgo se vería imposibilitada:

19 Van Liefferinge, en su estudio (1999, p. 125) pone de manifiesto este carácter inmanente de lo divino en la que se fundamenta la noción de simpatía universal. Este carácter ha de ser tomado en cuenta para comprender en profundidad la hermenéutica de los rituales paganos que lleva a cabo Jámblico.

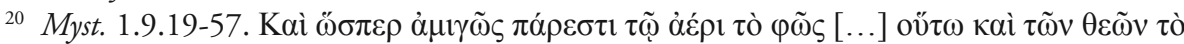

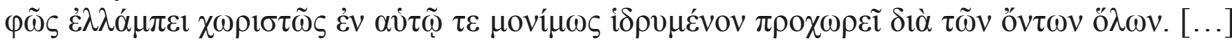

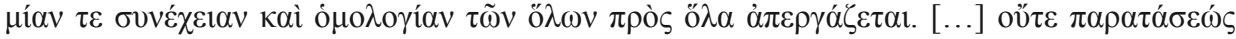

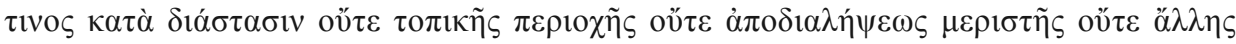

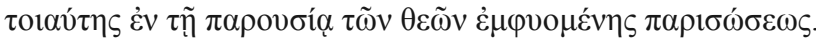


No veo además de qué modo las cosas de aquí son creadas y especificadas, si ninguna actividad creadora divina y participación de las ideas divinas se extienden por el mundo entero. Esta opinión ${ }^{21}$ aniquila por completo el culto sagrado y la comunidad teúrgica de los dioses con los hombres, al expulsar fuera de la tierra la presencia de los seres superiores. No otra cosa quiere decir sino que las cosas divinas están lejos de las de la tierra, que no se mezclan con los hombres y que este mundo está privado de ellas. [...] pero nada de ello es sensato, pues ni los dioses son retenidos en partes del mundo, ni la tierra está privada de ellos. Por el contrario, los seres superiores en el mundo, lo mismo que no están contenidos por nada, contienen todo en sí mismos, mientras que las cosas de la tierra tienen su existencia en la plenitud de los dioses ${ }^{22}$.

"Las cosas de la tierra tienen su existencia en la plenitud de los dioses ( $\tau \grave{\alpha}$

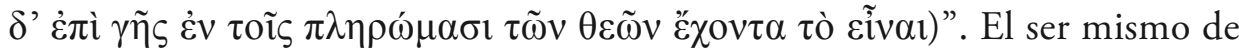
las cosas del mundo está incardinado en la potencia creadora del principio. El principio divino se revela, así, a través de los seres, permaneciendo como

${ }^{21}$ La opinión a la que se alude en este pasaje es la referida por Porfirio, según la cual lo divino estaría limitado a diversos cuerpos: "su asignación a diferentes cuerpos, por ejemplo, de los dioses a cuerpos etéreos, de los démones a aéreos, de las almas a los terrestres, es causa de la distancia actualmente investigada" (Carta a Anebo I 2a Sodano).

A ello contesta también Jámblico en Myst. 1.9.3-6, afirmando que: "En absoluto es verdad el punto de partida, que en el cielo los dioses andan dando vueltas solo, pues todo está lleno de ellos", haciendo referencia a la conocida afirmación de Tales (Cf. 11 A 2, 11 A 3, 11 A 23 DielsKranz).

La comprensión de lo divino, que Jámblico intenta poner de manifiesto, se aparta, como decimos, de la concepción que supone a los dioses como entes, constituyendo éstos una alteridad frente a un sujeto que puede influir en ella en su propio beneficio. Según esta concepción, en la que se basa parte de la hermenéutica contemporánea de los textos de Jámblico desde Dodds, los símbolos que despliega la teúrgia serían concebidos como puentes tendidos hacia una realidad ajena.

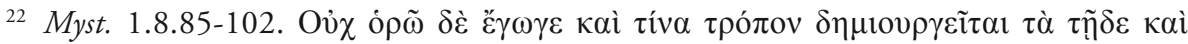

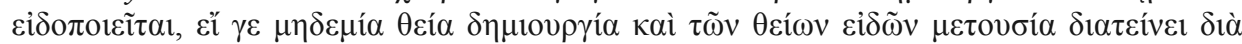

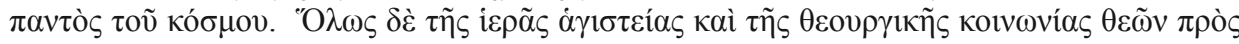

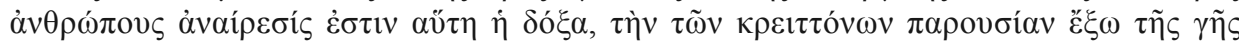

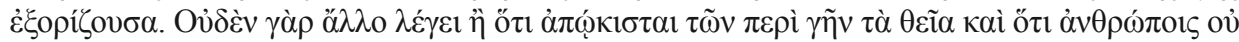

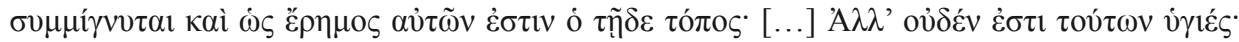

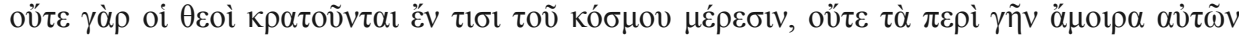

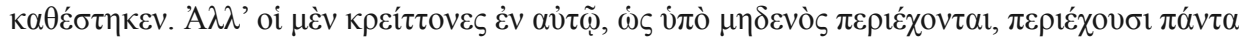

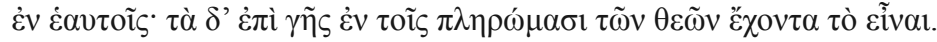


no manifiesto, como no reducido a ente. La realidad adquiere una cualidad simbólica, infinitamente abierta al principio que la constituye.

La creación divina despliega toda una serie de mediaciones que permiten el surgimiento de la multiplicidad como manifestación de la unidad. El proceso demiúrgico consiste en la introducción de medida en lo inefable, dando lugar a las formas que, de un lado, manifiestan su fundamento, pero que, de otro lado, lo ocultan. Se tornan, pues, una imagen simbólica que muestra la presencia de lo divino en la forma de no manifiesto que le es propia.

En la realidad convergen lo sensible y lo inteligible; adquiriendo con ello el aspecto simbólico que le es constitutivo. El camino epistémico que inaugura lo simbólico no consiste en trasladarse de un lugar a otro, ni en establecer una relación determinada con entidad alguna, sino en ahondar, a través de la proporción que procura el símbolo, en la naturaleza inteligible de la realidad ${ }^{23}$.

Tal es la relación con lo divino que persigue Jámblico a través de las mediaciones que despliega el marco del símbolo y el ritual. La búsqueda de la apertura a la contemplación inteligible de lo real que constituye el telos fundamental de la filosofía platónica es mantenida por Jámblico en todo momento. Tal finalidad es utilizada para dar coherencia y vigor al marco religioso de la sociedad pagana. En ella se vertebra y toma su sentido, como veremos, la actividad del teúrgo.

\section{La naturaleza del teúrgo a la luz de la comprensión de la figura del filósofo.}

Sobre la planta de la auténtica filosofía, dibuja Jámblico su comprensión del ámbito de los símbolos y los rituales. Su método, su potencia de trasformación del alma, de purificación y de liberación de la mirada, su capacidad para abrir una vía de acceso a lo divino, son entendidas desde el método y el poder de transformación del alma de la filosofía platónica. Así, la noción de teúrgia que

${ }^{23}$ Para un estudio en profundidad de esta cuestión remitimos a Hermoso Félix, 2012, p. 246 ss. 
hallamos en el De Mysteriis corre paralela a la noción de la verdadera filosofía que encontramos en el Protréptico ${ }^{24}$. En Protréptico 70.10 leemos:

La filosofía parece proporcionarnos la evasión de los vínculos humanos, la liberación de la generación, el retorno al ser, el conocimiento de la auténtica verdad y la purificación de las almas. Y si en esto consiste la verdadera felicidad, hay que esforzarse por la filosofía, si queremos realmente ser bienaventurados. ${ }^{25}$

Esta comprensión de la filosofía como camino de purificación y de liberación del alma sirve de planta a la comprensión de la teúrgia que aparece en $D e$ Mysteriis 10.7. La función del teúrgo se incardina en esta tarea de purificación y liberación del alma, que busca el acceso a la naturaleza inteligible:

Los teúrgos no turban el intelecto divino con cosas de poca importancia, sino con las que conducen a la purificación, la liberación y la salvación del alma; ni ellos se ocupan de cosas inútiles y difíciles para los hombres, sino,

${ }^{24}$ Van Liefferinge (1999, p. 31 ss.) marca acertadamente esta estrecha relación entre la noción de filosofía que encontramos en el Protréptico y la noción de teúrgia que encontramos en el $D e$ Mysteriis. Poniendo de manifiesto estos paralelismos y atendiendo a la imposibilidad de delimitar cronológicamente la anterioridad del Protréptico sobre el De Mysteriis, propone que la noción de teúrgia estaría vinculada con el aspecto práctico de la filosofía, de la que sería una continuación natural. Por otra parte, apunta acertadamente que la filosofía en Protréptico 88.7 queda concebida

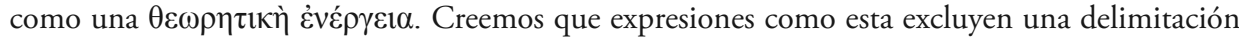
cerrada entre una filosofía teorética, dedicada exclusivamente a la contemplación y una filosofía práctica dedicada a la actividad. La actividad puesta en juego por la teúrgia es contemplativa, se da precisamente como suelo de contemplación. De otro lado, la contemplación es un cierto tipo de ÉvÉ $\rho \gamma \varepsilon 1 \alpha$, no habla de una pasividad contrapuesta a la acción sino de un cierto tipo de actividad. No creemos, por ello, que la teúrgia quede comprendida en Jámblico como una derivación de una filosofía práctica. Antes bien, nos inclinamos por la hipótesis de que es la comprensión de la filosofía platónica en su integridad la que sirve de marco de exégesis y dignificación de la teúrgia.

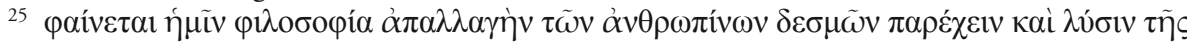

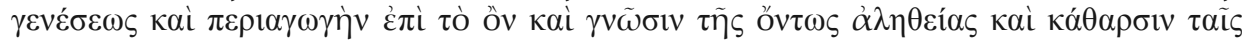

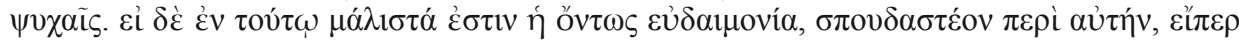

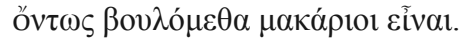


por el contrario, de las más útiles de todas para el alma; [...] ellos que se elevan a la naturaleza inteligible y divina. ${ }^{26}$

Los símbolos que despliega el teúrgo no actúan sobre los dioses, concepción ésta fuertemente rebatida por Jámblico como uno de los mayores malentendidos que dañan la verdadera comprensión de la efectividad del ritual. Estos actúan sobre la mirada del hombre, sobre su capacidad de apertura a la naturaleza inteligible. Al igual que la filosofía, la teúrgia busca liberar al alma de las cavernas de sus propias pasiones como vía hacia la experiencia de lo divino. El símbolo no busca suscitar pasión alguna sino liberar al alma de las pasiones que la mantienen alejada de una experiencia más honda de lo real y de sí. En Myst. 3.24.10 leemos: "¿Qué tiene la pasión de apropiado para la contemplación de los seres? ¿Por qué no es más bien un impedimento para una observación más verdadera?"27

El teúrgo, como el filósofo, es aquél que ha sido liberado de las pasiones, que ha ordenado su alma en la convivencia con lo divino y ordenado: "reciben toda virtud, se hacen honestos de costumbres y ordenados, se liberan de las pasiones y de todo movimiento desordenado, se purifican de las maneras ateas e impías"28 leemos en De Mysteriis 3.31.13. Del mismo modo son referidos en Protréptico 69.24 los genuinos amantes del saber que, siendo liberados de las pasiones por la filosofía, "son valerosos y ordenados" 2 . Jámblico se incardina aquí en la comprensión del filósofo que encontramos en República 500d: "Por convivir con lo divino y ordenado el filósofo se hace todo lo ordenado y divino que puede serlo un hombre"30.

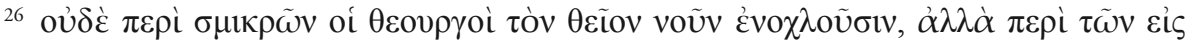

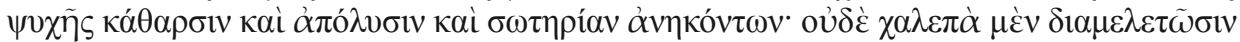

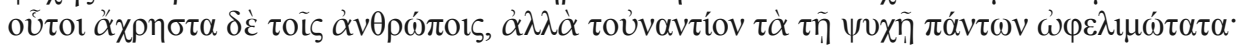

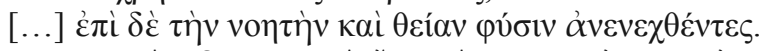

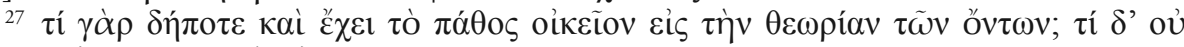

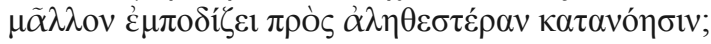

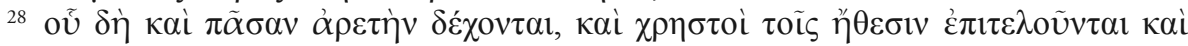

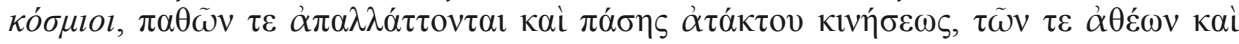

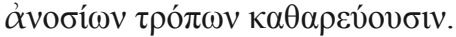

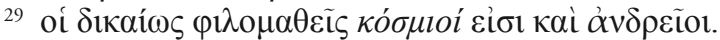

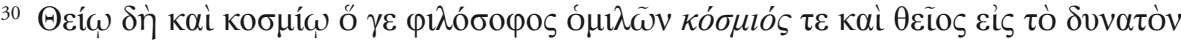

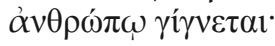


La tarea misma del camino de trasformación propuesto por la filosofía, ordenar el alma de acuerdo a la ordenación y el equilibrio propio de lo divino, alumbra la comprensión de la operatividad de la teúrgia. Tanto los filósofos como los

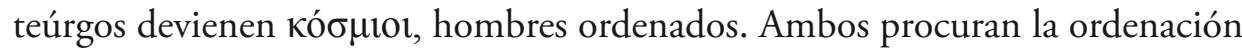
del alma que ha de propiciar su semejanza y su contacto con lo divino.

\section{Mediaciones filosóficas y mediaciones teúrgicas: símbolo ritual y belleza natural.}

La filosofía platónica apunta a las mediaciones que pueden facilitar esta ordenación del alma, esta alquimia y este ensanchamiento de la mirada: la contemplación de la armonía y el equilibrio del Universo, la atracción que ejerce la belleza del mundo, provocan una unificación paulatina del alma, su adentramiento gradual en la cualidad divina de lo real.

Jámblico extiende el poder de ordenación del alma que tiene la contemplación de la armonía del Universo en el Timeo y el poder de atracción de la belleza en el Banquete a su comprensión de la potencia simbólica de las prácticas rituales. El símbolo imita la constitución del Universo, su conformación en el orden y la armonía de lo inteligible adquiriendo su poder de ordenación y de reequilibrio de los movimientos internos del alma, su potencia para asemejar el alma a lo divino ${ }^{31}$.

La actividad del teúrgo está fuertemente vinculada a esta potencia epistémica del símbolo; en De Mysteriis 6.6.2, apunta Jámblico: "qué poder tiene por su unión con los dioses, otorgado por el conocimiento de los símbolos inefables". El teúrgo toma su lugar propio en el pensamiento de Jámblico como figura que guía al hombre en la apertura del alma hacia el principio fundamental de la realidad. El símbolo se torna ahora un elemento central en esta paideia del alma que procura el teúrgo. Éste, a través del símbolo, imitará la actividad misma de lo divino en la creación:

31 Este proceso de imitación y de semejanza a lo divino a través de la mediación que puede allegarse al alma y prepararla, purificarla y ordenarla, sirve el marco de comprensión del símbolo. La mistagogía oculta en los símbolos a la Jámblico se refiere en De Mysteriis 7.1.7, imita a la iniciación misma que la armonía del Universo, su constitución en lo inteligible, puede transmitir al alma. Esta mistagogía, esta iniciación, consiste en una alquimia de la mirada, en una ordenación, en un reequilibrio, que despiertan en ella su capacidad de experiencia de lo divino. Para un estudio detenido de esta cuestión, cf, Hermoso Félix, 2012, p. 295 ss. 
Estos, imitando la naturaleza universal y la creación divina, producen por medio de símbolos algunas imágenes de las intelecciones místicas, ocultas e invisibles, del mismo modo también que la naturaleza ha modelado por medio de símbolos los principios invisibles bajo formas visibles y que la creación divina ha esbozado la verdad de las ideas a través de imágenes visibles. Sabiendo, pues, que todos los seres superiores gozan con la semejanza de los inferiores y queriendo colmarlos de bienes mediante la imitación en cuanto es posible, reproducen con razón el modo apropiado de la mistagogía oculta en los símbolos. ${ }^{32}$

El teúrgo imita la actividad simbolizadora de la naturaleza. Ésta modela por medio de símbolos los principios invisibles bajo formas visibles. El teúrgo produce, por medio de símbolos, imágenes de las intelecciones místicas, ocultas e invisibles. Éste trae al ámbito de lo humano la productividad creadora de la

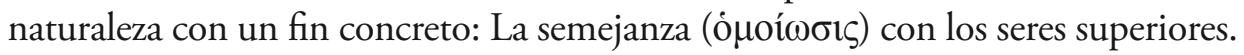

La semejanza a lo divino que buscó siempre la filosofía de raigambre platónica se procura ahora a través de los símbolos, como mediación que imita la actividad misma de la naturaleza. En la comprensión del símbolo se cifra uno de los elementos fundamentales en los que ha de apoyarse la exégesis de la figura del teúrgo. La novedad que introduce esta figura respecto del filósofo apunta a la cualidad misma de las mediaciones que utiliza. Estas mediaciones se inspiran, como decimos, en las que se encuentran en la obra platónica y, a la vez, introducen una novedad. Ambos aspectos han de ser tomados en cuenta en nuestro estudio.

Hay en el pensamiento de Jámblico un elemento indiscutible de continuidad con la filosofía platónica y un elemento de novedad que viene servido por la tarea de exégesis de los rituales paganos que éste lleva a cabo. El símbolo ha

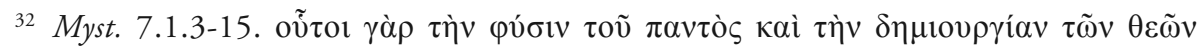

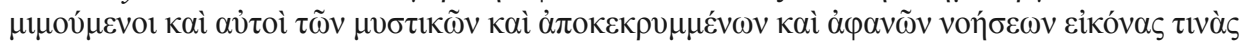

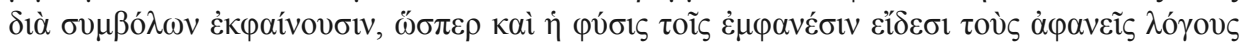

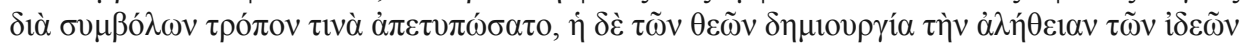

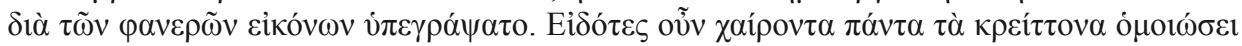

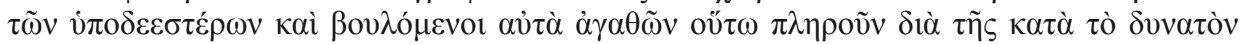

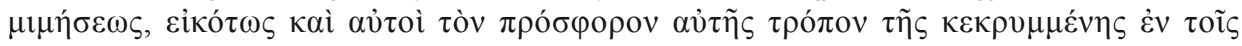

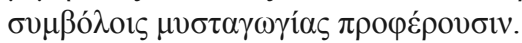


de comprenderse teniendo siempre esto a la vista: sin su incardinación en las mediaciones que presenta la obra platónica quedaría incomprendido; sin la toma en consideración de su novedad perderíamos una parte importante del nervio propio del pensamiento de Jámblico.

\section{Conclusión}

La función del teúrgo en la filosofía de Jámblico viene vinculada a la función del símbolo y a la comprensión del estatuto propio del conocimiento simbólico. La mediación que lleva a cabo no consiste en comunicar con entidades que se hallarían en otro lugar para influir en ellas, consiguiendo algún beneficio o evitando algún daño. Esta concepción, como hemos visto, es largamente criticada en el De Mysteriis, en cuyas páginas encontramos una concepción de lo divino no susceptible de entificación. Lo divino constituye el plano mismo de causación en el que se sustenta cuanto es y deviene. Jámblico, lejos de proponer una serie de prácticas cercanas a la magia vulgar para influir en la divinidad, propone mediaciones que faciliten el camino de apertura de la mirada del alma a su naturaleza primera. El telos de la filosofía platónica, la semejanza a lo divino, es seguido en todo momento por este pensador. Éste lleva a cabo una relectura del ámbito del ritual por una apremiante necesidad histórica: hacer frente a una religión universalista que amenazaba seriamente el modo de conformación sociocultural del helenismo. Esta exégesis del marco ritual pagano se hace sobre la planta de la filosofía platónica, sobre las mediciones que ésta propone, sobre su naturaleza y su funcionamiento. Con este intento, como apunta acertadamente Charles-Saget, Jámblico se convierte en "le premier philosophe qui ait ouvert à l'ensemble des symboles l'espace de la réflexion philosophique. Ce sont l'anthropologie, la psychanalyse et l'histoire des religions qui en on à notre époque repris l'étude" (1993, p. 113). 


\section{Bibliografía básica.}

\section{Fuentes}

Platón. Fedón, Banquete, Fedro (trad. castellana de C. García Gual, M. Martínez Hernández y E. Lledó Ińigo) Madrid: Gredos, 1986.

Jámblico. Sobre los misterios egipcios (trad. castellana de E.R. Ramos Jurado), Madrid: Gredos, 1997.

Les mystères d'Egypte (Texte éd. et trad. par É. des Places), París : Les Belles Lettres, 1966. Vida pitagórica (trad. castellana de E.R. Ramos Jurado), Madrid: Gredos, 1997.

Protréptico (trad. castellana de M. Periago Lorente), Madrid: Gredos, 2003.

Jamblique.

Plotino. Enéadas (trad. castellana de J. Igal), Madrid : Gredos, 1998.

\section{Estudios}

Blumenthal, H.J. - Clark, E.G. (1993): H.J. Blumenthal - E.G. Clark (ed.) The divine Iamblichus, philosopher and Man of Gods, Bristol: Bristol Classical Press.

Blumenthal, H.J. - Finamore, J.F. (1997): H.J. Blumenthal - J.F. Finamore (ed.), Iamblichus: the philosopher, Iowa: University o Iowa.

Clarke, E.C. (2001): Iamblichus' De mysteriis. A manifesto of the miraculous, Aldershot: Alsgate.

Bernabé, A. (2011): Platón y el orfismo. Diálogos entre Religión y Filosofía. Madrid: Abada.

Des places, E. (1981): "La religion de Jamblique", Études Platoniciennes, Leiden : Brill, 329-359.

Des places, E. (1981) : "Platon et la langue des mystères", Études Platoniciennes, Leiden : Brill, 83-98.

Des places, E. (1969): La religion grecque. Dieux, cultes, rites et sentiments religieux dans la Grèce antique, París.

Dodds, E.R. (1951): The Greeks and the irrational, (trad. esp. M. Araujo, Madrid: Alianza, 1994), Berkeley: Univ. of California Press.

Dodds, E.R. (1965): Pagan and Christian in an Age of Anxiety, Cambridge: Cambridge University Press.

Dillon, J. (2004): J. Dillon, Lloyd P. (ed.), Neoplatonic philoshophy introductory readings, Indianapolis: Hackett Publishing Company. 
Hadot, P. - HADOT, I. (2004) : Apprendre à philosopher dans l'Antiquité, París : Libraire Générale Française.

Нadot, P. (2002) : Exercices spirituels et philosophie antique, París : Albin Michel.

Autor (2008): "La comprensión de lo divino en el pensamiento de Jámblico: alma, símbolo y conocimiento", Politeísmo y encuentro con el Islam, G. Vattimo - T. Oñate (ed.) Madrid: Dykinson, 385-397.

Autor (2012): "El símbolo en el De mysteriis de Jámblico: La mediación entre el hombre y lo divino", Madrid: eprints.ucm.es, 2012.

Larsen, B.D. (1972) : Jamblique de Chalcis, exégète et philosophe, Aarhus : Universitetforlaget.

Liefferinge, C. V. (1999): La théurgie. Des Oracles Chaldaïques à Proclus, Liege : Kernos.

Pepin, J. (1993) "L'initié et le philosophe", La pureté : quête d'absolu au péril de l'humain, Matton S. (ed.), París, p. 105-130.

SAfFrey, H.D. (1990): "La théurgie chez les néoplatoniciens", Le Néoplatonisme après Plotin, París : Vrin.

SAGET, C. (1993) "La théurgie, nouvelle figure de l'ergon dans la vie philosophique", The divine Iamblichus, Bristol : Bristol Classical Press.

Taormina, D.P. (1999): Jamblique critique de Plotin et Porphyre, París : Vrin.

Recibido : 28/01/2014

Aceptado : 1/09/2014

Este trabajo se encuentra bajo una licencia de Creative Commons ReconocimientoNoComercial-SinObraDerivada 4.0 
